\title{
Assessment of PTSD in Older Veterans: The Posttraumatic Stress Disorder Checklist: Military Version (PCL-M)
}

\author{
Jeffrey S. Yarvis \\ Eunkyung Yoon \\ Margaret Amenuke \\ Sandra Simien-Turner \\ Grace D. Landers
}

\begin{abstract}
The Posttraumatic Stress Disorder (PTSD) Checklist: Military Version (PCL$M)$ is a 17-item, self-report measure of PTSD symptomatology in military veterans and provides one total score and four subscale scores for older veterans' PTSD (reexperiencing, avoiding, numbing, and hyperarousal symptoms). Study subjects are 456 male veterans over 55-years old with deployed experiences selected from a larger survey data by Veterans' Affairs Canada (VAC). This study found that overall scale reliability was excellent with alpha of .93 and subscale alphas ranging from .81 to .90. Confirmatory Factor Analysis (CFA) confirmed the best fit of four first-order factor model. Criterion validity was confirmed through significant associations of the PCL-M scores with well-established measures of depression, substance abuse, and general health indices. The PCL-M is recommended as a reliable and valid tool for the clinical and empirical assessment of screening PTSD symptomatology, specifically related to older veterans' military experiences.
\end{abstract}

Keywords: Military Veterans; PTSD; Retrospective study; PCL-M; Canadian

\section{INTRODUCTION}

Since the 1970s, there has been a vital demographic trend in the Veterans Administration (VA). Although the total number of veterans is declining, the proportion of older veterans is increasing dramatically (Richardson \& Waldrop, 2003). Additionally, the proportion of older persons in the veteran population far exceeds the proportion of older persons in the U.S. population. Much of the VA's efforts are rightly focused on the emerging needs of recent veterans from the wars in Afghanistan and Iraq. However, there is a paucity of research on the psychological and physical needs of aging veterans.

In 2000, the median age of veterans was fifty-seven years, fifty-four in Canada (Veterans Affairs Canada, 1999), compared to only thirty-six years for the general U. S. population and 39 years for Canadians (Administration on Aging, 1999). Over 37 percent of the veteran population ( 9.5 million of the total 25.5 million veterans) was age sixtyfive or older, compared to 13 percent of the general population. By 2020, nearly half of the entire veteran population ( 7.6 million, or 45 percent, of the total 16.9 million

\footnotetext{
Lieutenant Colonel Jeffrey S. Yarvis, Ph.D., LCSW, is deputy commander for behavioral health, Dewitt Healthcare Network, Fort Belvoir, VA. Eunkyung Yoon, MSW, Ph.D., is Associate Professor at the School of Social Work, Jackson State University, Jackson, MS. Margaret Amenuke, MPH, and Sandra Simien-Turner, LCSW, are doctoral students at the School of Social Work, Jackson State University. Grace Landers, ENS, MC, USN, is a medical student at F. Edward Hebert School of Medicine, Uniformed Services University, Bethesda, MD.

Copyright (C) 2012 Advances in Social Work Vol. 13 No. 1 (Spring 2012), 185-202
} 
veterans) will be age sixty-five or older. Although most are male, the number of female veterans is growing. In 2000 , over 5 percent ( 1.4 million) of all veterans and 3 percent $(325,000)$ of veterans age sixty-five or older were female. By 2020, over 9 percent $(1.6$ million) of all veterans and 4 percent $(316,000)$ of veterans age sixty-five or older will be female. Among female veterans, the proportion age sixty-five or older was 23 percent in 2000 and is projected to be 20 percent in 2020. As in the general U.S. population, the "old-old" are the fastest-growing segment of the veteran population. By 2020, 6 percent of all veterans and 13 percent of veterans age sixty-five or older will be age eighty-five or older (1.1 million). Thus, VA and VAC will continue to encounter a very large group of potentially frail, older veterans in the next twenty years (Fitretoglu, Liu, Pedlar, \& Brunet, 2007).

One of the significant psychiatric conditions resulting from exposure to traumatic events such as conflict and war zone exposure is PTSD. The Diagnostic and Statistical Manual of Mental Disorders-IV-TR 2000 (American Psychiatric Association, 2000) criteria for PTSD requires exposure to a traumatic event involving actual or threatened death or serious injury. Multiple categories of traumatic events have been considered for PTSD that includes cancer, sexual harassment, hurricanes, and military peacekeeping operations (Asmundson, Stein, \& McCreary, 2002; Dirkzwager, Bramsen, \& Van Der Ploeg, 2005; DuHamel, et al., 2004; Forbes, Creamer, Hawthorne, Allen, \& McHugh, 2003; Gray, Bolton, \& Litz, 2004; Palmieri \& Fitzgerald, 2005; Richardson, Naifeh, \& Elhai, 2007). Categories, notwithstanding, the event must produce a response of intense fear, helplessness, or horror (Criteria A), and the experience of as many as 17 symptoms that are categorized in three symptom clusters: re-experiencing (Criteria B), avoidance or numbing (Criteria C), and arousal (Criteria D). The formal diagnosis of PTSD requires that an individual experience at least one of five re-experiencing symptoms, three of the seven avoidance or numbing symptoms, and two of five arousal symptoms and that the symptoms experienced have a duration of greater than one month (Criteria E). Additionally, the psychological disturbance causes significant distress or impairment in important areas of functioning such as social and occupational (Criteria F).

PTSD is associated with other psychological and emotional problems (Asmundson, Frombach, McQuaid, Pedrelli, Lenox, \& Stein, 2000; Asmundson, Wright, McCreary, \& Pedlar, 2003; Mehlum \& Weisaeth, 2002). Frequently co-morbidity with depression, anxiety, and alcohol and substance use has been studied (Asmundson, et al., 2002; Forbes, et al., 2003; Yarvis, Bordnick, Spivey, \& Pedlar, 2005; Yarvis \& Schiess, 2008). Major depression was the most common co-morbid diagnosis, occurring in just under half of men and women with PTSD in the National Co-morbidity Survey (Kessler, Sonnega, Bromet, Huges, \& Nelson, 1995). Additionally, PTSD was the primary diagnosis associated with the majority of cases in the development of affective disorders and substance use disorders (Kessler, et al. 1995). Persons with preexisting major depression had an increased and twofold risk for subsequent exposure to traumatic events and pre-existing depression increased the risk of PTSD among exposed persons more than threefold (Breslau, Davis, Peterson, \& Schultz, 2000). Further, the wars in Afghanistan and Iraq have resulted in higher mental health utilization by U.S. Veterans (Hoge, Auchterlonie, \& Milliken, 2006). 
As wars and conflicts continue, there is increasing concern for soldiers in combat zones, many of whom are at high-risk for PTSD (e.g., Gray, Bolton, \& Litz, 2004; Helmer, Rossignol, Agarwal, Teichman, \& Lange, 2007). Given rising deployments of military forces on asymmetric missions to various conflict zones, it is important to better understand the risk factors for PTSD of these veterans. Research on the prevalence of traumatic exposure has tended to focus on younger populations. Specifically, there is a need for research regarding PTSD identification in older veterans (Cook, Elhai, Cassidy, Ruzek, Ram, \& Sheikh, 2005). The goal of this study about trauma and its effect in older adults, especially veterans and recent war veterans is to contribute to a knowledge gap. The specific purpose of the present study is to evaluate the overall psychometric properties of the PCL-M using the sample of old Canadian peacekeepers.

\section{MATERIALS}

The PTSD Checklist (PCL) was developed by Frank W. Weathers and colleagues at the National Center for PTSD (Weathers, Litz, Herman, Huska, \& Keane,) and has three adult versions, the military (PCL-M), civilian, unspecified event (PCL-C), and the civilian, specified event (PCL-S). The PCL-M is an adult 17-item self-report instrument that assesses PTSD symptoms in relation to stressful military experiences. Respondents rate each item from 1 ("not at all") to 5 ("extremely") to indicate the degree to which they have been bothered by that particular symptom over the past month. Thus, total possible scores range from 17 to 85 . PTSD symptom severity scores are determined by summing the participants' answers to all 17 items. The standard procedure for determining PTSD is to compute the questionnaire's three subscales: re-experiencing, avoidance/numbing, and hyper-arousal. When the PCL-M is used as a continuous measure, a cut-off score of 3 or more for each item is the most appropriate (Forbes, Creamer, \& Biddle, 2001; 1993Weathers et al., 1993). A cutoff score of 50 on the PCL-M yielded a sensitivity of .82 , specificity of .83 , and a $\mathrm{K}^{\prime}=.64$ in the original sample of U.S. Vietnam and Gulf War veterans (Weathers, et al. 1993). However, other subsequent studies with different populations have suggested that lower cutoff scores, 30,31,37, and 38 more accurately identify individuals with PTSD respectively (Andrykowski, Cordova, Studts, \& Miller, 1998; Cook, Elhai, \& Arean, 2005; Dobie, et al., 2002; Yeager, Magruder, Knapp, Nicholas, \& Frueh, 2007).

The PCL has proven to be a psychometrically sound instrument for screening PTSD (Weathers, et. al, 1993). The test retest reliability was .96, $\alpha=.93$ for Criteria B symptoms, $\alpha=.92$ for Criteria $\mathrm{C}$ symptoms, $\alpha=.92$ for Criteria D symptoms, with an overall $\alpha=.97$ for all items (Weathers, et al., 1993). Another study reported similar internal consistency values (Blanchard, Jones-Alexander, Buckley, \& Forneris, 1996). It is noted that there has been no normative data published. According to Asmundson's study (Asmundson, et al., 2000), the PCL-M has good contrasted-groups validity and sound convergent validity. Strong correlations have been shown between the overall PCL-M and other scales designated to measure PTSD (i.e., $r=.93$ with the Mississippi Scale for Combat-related PTSD (Keane, Caddell, \& Taylor, 1988); $r=.90$ with the Impact of Events Scale (Horowitz, Wilner, \& Alvarez, 1979)). 
There are constant debates on the construct validity. The DSM-IV's factor structure of PTSD is a higher-order 3-factor model with three first-order symptom factors and a second order PTSD factor. Some researchers using Confirmatory Factor Analysis (CFA) find that PTSD data fits 4-factor models better (Asmundson, et al., 2002; Asmundson, et al., 2003; Simms, Watson, \& Doebbelling, 2002). Elklit and Shevlin (2007) tested a fourfactor PTSD model that was re-structured using the DSM-IV's 3-factor structure. These factors include re-experience, avoidance, dysphoria, and arousal. There is also evidence that two-factor solutions may have utility as well. Two studies reported that a 2-factor model consisting of one overarching (second-order) latent factor (posttraumatic stress) and two first-order factors of re-experiencing and avoidance (items B1-B5 and items C1C2) and numbing and arousal (items D1- D5 and C3- C7) was a better fit (Buckley, Blanchard, and Hickling, 1998; Taylor, Kuch, Koch, Crockett, \& Passey, 1998). Simms and colleagues (2002) predicted that factors representing non-specific components of PTSD would have the highest associations with variables representing depressive symptomatology. Asmundson and colleagues (2003) suggest that PTSD symptoms in military veterans can be adequately conceptualized using hierarchical two-factor or fourfactor inter-correlated models.

Several recent studies have focused on measuring PTSD symptomatology in older adults as an indicator of the impact of trauma using the PCL (Cook, Elhai, \& Arean 2005; Cook, Riggs, Thompson, Coyne, \& Sheikh, 2004; Cook, Elhai, Cassidy, et.al., 2005; Schinka, Brown, Borenstein, \& Mortimer, 2007; Schnurr, Spiro, Vielhauer, Findler, \& Hamblen, 2002). A CFA of the PCL conducted with a sample of elderly hurricane survivors (Schinka, et al., 2007) revealed the strongest model support for an intercorrelated 4-factor model comprised of re-experiencing, avoidance, numbing, and arousal factors. Similarly, this array of factors, supported by Keen (Keen, Kutter, Niles, $\&$ Krinsley, 2008) in their study of male veterans suggested the avoidance and numbing symptoms of Cluster $\mathrm{C}$ are more distinct than they are similar. However, there have been limited studies, which have specifically investigated PTSD in veterans of peacekeeping missions and from the conflicts in Iraq and Afghanistan (Richardson, et al., 2007). Few have studied the PCL-M with older veterans. Additional research is needed to further the understanding and knowledge base regarding the PTSD symptom structure in the context of chronic, repeated, and varied trauma exposures in peacekeeper populations.

The purposes of this study are to (1) investigate the prevalence and severity of PTSD among older Canadian peacekeepers with deployed experiences, (2) evaluate the overall psychometric properties of the PCL-M with older male veterans, and (3) confirm factor structure of the PCL-M with testing alternative CFA models drawn from previous studies.

\section{Source of Data}

The present study used the secondary data as part of a health status assessment conducted by VAC. With permission from the Department of National Defense Canada and the Research Director of VAC, Prince Edward Island, VAC provided data to the first author in 2004. The data used was based on a mail-out survey conducted September through December, 1999 by the Review of Veterans' Care Needs Project, VAC. The 
dataset received from the VAC contained 1968 observations (1856 male, 112 female) consisting of 411 variables from a questionnaire given to Canadian military personnel in the fall, 1999. This survey was restricted to VAC pensioners living in Canada and was originally conceptualized to address gaps in support and services. Creatic + , a Montreal based research firm, reported a 72 percent response rate, and 96 percent of the respondents filled out the questionnaire on their own. Thus, the current sample of respondents is considered to be representative of the VAC Canadian Force (CF) population (Asmundson, et al., 2000). For the present research, study subjects included 456 male United Nations peacekeepers over the age of 55 years. This sample was selected from a larger sample of 1968 regular and reserve force Canadian military personnel with three criteria: being male, having been deployed overseas to a conflict more than one time, and being 55 years or older.

\section{Measurement}

The original survey was comprised of 411 variables with seven domains. For the purposes of this study, in addition to the PCL-M, only major selected variables were described as below.

Center for Epidemiologic Studies-Depression (CES-D) Scale (Radloff, 1977): Canadian veteran's depression was assessed with the CES-D, a 20 item self-report scale of depressive symptoms according to frequency of occurrence from less than 1 day per week to 5-7 days per week. The CES-D has been reported to have good reliability in studies with the elderly (Radloff \& Terri 1986) and provided good agreement with other measures of depression. Total scores range from 0 to 60 , with higher scores indicating more depressive symptoms. The mean score for both younger and older adult subjects in the general population respectively is 9 , with 16, a useful cut-off for screening subjects who likely experience a significant level of depression (Radloff \& Terri, 1986). In this study, the Cronbach alpha is .905 and the mean CES-D score for older male veterans with deployed experience is 13.84 ( $\mathrm{SD}=7.53$, range $=0-60$ ), indicating that overall older veterans were more depressed than that of the general population. Accordingly, with the 16 cut-off score, approximately $27.8 \%$ of the total sample can be diagnosed as seriously depressed.

Alcohol Use Disorders Identification Test (AUDIT) was developed by the World Health Organization for multinational use in primary care settings and evaluated over a period of two decades (World Health Organization, 2001). As a core screening assessment tool, the original AUDIT consists of 10 questions about recent alcohol use, alcohol dependence symptoms, and alcohol-related problems. The AUDIT was validated on primary health care patients in six countries. In comparison to other screening tests, the AUDIT has been found to perform equally well or at a higher degree of accuracy across a wide variety of criterion measures such as MAST $(r=.88)$ and CAGE $(r=.78)$ (WHO, 2001). A test-retest reliability study indicated higher reliability $(r=.86)$ in a sample consisting of non-hazardous drinkers. In this study, two domains were created to separately assess frequency of use and dependency. Alcohol use and problems via the AUDIT are summarized in the 1999 Regular Forces Dataset by the variables QFINDEX and ALCPROB. The QFINDEX included questions pertaining to how frequently alcohol 
is consumed during a specific time period and how many drinks are consumed on a typical drinking occasion. The ALCPROB focused on "alcohol-related" problems with questions related to problems with alcohol and negative consequences linked from alcohol consumption (i.e. going to work intoxicated). The overall alpha level is .802 .

General Health Indices consisted of three components. A single question was used to measure self-rated health status. For example, the question ("Compared to other people your age, would you say that in general your health is?") had four possible answers from 1 (excellent) to 4 (poor). In a previous study, a one-item measure of perceived health was found to be correlated positively and significantly with the overall score of a 20 -item health-related quality of life measure with established validity and reliability (Musick, 1996). The second component included queries of older veterans on the possibility of them having any long-term conditions diagnosed by a health professional among 21 specific conditions on a list. This list included common physical problems among older adults, such as Arthritis and Rheumatism, Depression, Diabetes, High Blood Pressure, vision and hearing problems. Consistent with the other outcome variables, a higher score on the scale indicates a worse overall perceived health status. Lastly, the respondents were asked to answer how many medications, both prescribed and non-prescribed they are currently taking.

\section{Data Analysis}

Data analysis consisted of a CFA of the two, three, and four factor, latent variable models. CFA involved a structural equation model (SEM) using the PRELIS 2.8 and LISREL 8.8. By default, the LISREL uses the maximum likelihood (ML) method of parameter estimation. Several researchers supported the argument that ML is found to perform well under less than optimal analytical conditions (for example, small sample sizes and modest departures from multivariate normality) (Kline, 2011). Thus, considering a moderate abnormal distribution of the data, ML is adopted to be a reasonable estimation method for this study. Several measurement models were tested using LISREL Version 8.80 with a covariance matrix generated by PRELIS Version 2.8.

The goodness of fit statistics used in the present study to assess model fit are as follows: (1) Chi-square $\left(\chi^{2}\right)$ and degree of freedom (df), (2) the Goodness-of-Fit Index (GFI), (3) the Comparative Fit Index (CFI), (4) the Non-Normed Fit Index (NNFI), (5) the Root Mean Square Error of Approximation (RMSEA) which all fit measures that are well explained in most cited textbooks (Kline, 2011). Chi-square $\left(\chi^{2}\right)$ as the traditional absolute fit measure is used to test the closeness of fit between the hypothesized model and the perfect fit (Kline, 2011). A smaller $\chi^{2}$ value is indicative of good fit, whereas a large value reflects poor fit (Hu \& Bentler, 1999). As with the GFI, values of CFI range from zero to 1.00 , with values closer to 1.00 and are indicative of good fit, and .90 is the 'critical value' that indicates acceptable fit (Mueller \& Hancock, 2007). Similar to the CFI, the NNFI compares how much better the model fits compared to a baseline model (Hu \& Bentler, 1999; Kline, 2011). Finally, by taking into account the error of approximation in the population, the RMSEA's values of less than .05 indicates a good fit, values as high as .08 represent reasonable errors of approximation in the population, and values above .10 indicate mediocre fit ( $\mathrm{Hu} \&$ Bentler, 1999). Because different 
indices reflect different aspects of model fit, researchers typically report the values of multiple indices as mentioned above.

\section{RESULTS}

Table 1 presents sample characteristics. The majority of the selected sample is Anglo $(88.2 \%)$. In the highest level of education and training, persons not completing secondary schooling are $34.7 \%(\mathrm{n}=150)$, completed high school $(\mathrm{n}=98,22.7 \%)$, some postsecondary education $(\mathrm{n}=85,18.6 \%)$, completed diploma and post secondary $(\mathrm{n}=74$, $16.2 \%$ ). Around $90 \%$ of participants are married under common law. Regarding present rank or rank on their release, non-commissioned officers are the majority $(n=308,67.5 \%)$ and both senior and junior officers are $25 \%(n=103)$. The average number of unique deployment is $1.37(\mathrm{SD}=.647)$ with the average number of years served being 20 years $(\mathrm{SD}=12 \mathrm{yrs})$. Forty-two percent have a total individual income of less than $\$ 20,000$ in the previous year, $24.3 \%$ have an income between $\$ 20,001$ and $\$ 30,000,18.2 \%$ between $\$ 30,001$ and $\$ 40,000$, and $13.2 \%$ between $\$ 40,001$ and $\$ 50,000$.

Table 1 also consists of descriptive statistics of selected variables. In the single-item reporting self-rated health condition, the majority of respondents assessed their general health condition as either good $(37.5 \%)$ or fair $(37.9 \%)$, while 71 persons $(15.6 \%)$ rate 'poor'. Out of a total of 21 physical health conditions, the mean number is 3.63 ( $\mathrm{SD}=$ 2.17 ) with a score range between 0 and 14 . Forty-one percent of respondents report having unspecified other long-term conditions $(n=175)$, the top three of which are Arthritis or Rheumatism (62.9\%), back problems excluding Arthritis (60\%), and High Blood Pressure (30.8\%). Concerning more critical chronic conditions, $14.4 \%$ of respondents are suffering with Diabetes, while with Heart Disease $(20.3 \%)$, even Cancer (7.1\%), and Stroke (6.6\%).

Table 2 summarizes descriptive results of individual items for each factor, the mean and standard deviations with score range and distribution. As stated earlier, instruction starts with how each problem may or may not have affected you and following questions like "Had repeated disturbing dreams of your military experiences?" and score ranges from 1 to 5, with 1 indicating no and 5 indicating extremely. The mean score for the severity ratings on the total score is 23.73 ( $\mathrm{SD}=8.72$, range $=17 \sim 83)$. The descriptive statistics on the subscales are as follows: Re-experiencing $(\mathrm{M}=6.80, \mathrm{SD}=3.78)$, Avoiding $(\mathrm{M}=2.60, \mathrm{SD}=1.58)$, Numbing $(\mathrm{M}=7.03, \mathrm{SD}=3.5)$, and Hyper-arousal $(\mathrm{M}=8.39, \mathrm{SD}=4.40)$. Among individual items, the rating of two items - sleep difficulties and diminished interests - are relatively higher than others. 
Table1: Descriptive Statistics of Selected Variables $(\mathrm{N}=\mathbf{4 5 6})$

\begin{tabular}{|c|c|c|c|c|c|}
\hline Variables & Number & $(\%)$ & Range & Mean & (SD) \\
\hline \multicolumn{6}{|l|}{ Demographics } \\
\hline Age & & & $55-76$ years old & 60.53 & (3.116) \\
\hline $\begin{array}{l}\text { Education: } \\
\text { Secondary Not completed } \\
\text { Completed Secondary } \\
\text { Some Post-Secondary } \\
\text { Completed Diploma } \\
\text { Complete Bachelor }+\end{array}$ & $\begin{array}{r}150 \\
98 \\
85 \\
74 \\
25\end{array}$ & $\begin{array}{l}(32.9) \\
(21.5) \\
(18.6) \\
(16.2) \\
(05.5)\end{array}$ & & & \\
\hline $\begin{array}{l}\text { Individual Income } \\
\text { Less than } \$ 19,999 \\
\$ 20,000 \text { and } \$ 29,999 \\
\$ 30,000 \text { and } \$ 39,000 \\
\$ 40,000 \text { and } 49,000 \\
\$ 50,000 \text { over }\end{array}$ & $\begin{array}{r}78 \\
111 \\
83 \\
60 \\
55\end{array}$ & $\begin{array}{l}(17.1) \\
(24.3) \\
(18.2) \\
(13.2) \\
(09.3)\end{array}$ & & & \\
\hline $\begin{array}{l}\text { Marital Status } \\
\text { Married/Common Law } \\
\text { Not Married }\end{array}$ & $\begin{array}{r}407 \\
48\end{array}$ & $\begin{array}{l}(89.3) \\
(10.5)\end{array}$ & & & \\
\hline \multicolumn{6}{|l|}{ Military-Related } \\
\hline $\begin{array}{l}\text { Number of Years Served } \\
\text { Number of Deployments }\end{array}$ & & & $\begin{array}{c}1-45 \\
1-4\end{array}$ & $\begin{array}{r}19.89 \\
1.74\end{array}$ & $\begin{array}{l}(11.86) \\
(0.942)\end{array}$ \\
\hline \multicolumn{6}{|l|}{ Health-Related } \\
\hline $\begin{array}{l}\text { General Health Index } \\
\text { Excellent } \\
\text { Good } \\
\text { Fair } \\
\text { Poor }\end{array}$ & $\begin{array}{r}37 \\
171 \\
173 \\
71\end{array}$ & $\begin{array}{l}(08.1) \\
(37.5) \\
(37.9) \\
(15.6)\end{array}$ & $1-4$ & 2.62 & $(0.846)$ \\
\hline $\begin{array}{l}\text { Number of Health Problems } \\
\text { Arthritis or rheumatism } \\
\text { Back problem } \\
\text { High blood pressure } \\
\text { Cancer }\end{array}$ & $\begin{array}{r}275 \\
263 \\
135 \\
31\end{array}$ & $\begin{array}{l}(62.9) \\
(60.0) \\
(30.8) \\
(07.1)\end{array}$ & $0-14$ & 3.63 & $(2.175)$ \\
\hline Number of Medications & & & $0-25$ & 3.02 & $(3.171)$ \\
\hline $\begin{array}{l}\text { Alcohol Problems (AUDIT) } \\
\text { QFINDEX } \\
\text { ALCPROB }\end{array}$ & & & $\begin{array}{l}9-35 \\
2-10 \\
7-35\end{array}$ & $\begin{array}{r}11.61 \\
3.60 \\
7.57\end{array}$ & $\begin{array}{l}(2.65) \\
(1.61) \\
(1.54)\end{array}$ \\
\hline Depression (CES-D) & & & $0-60$ & 13.84 & $(7.53)$ \\
\hline
\end{tabular}


Table 2: $\quad$ Prevalence of the PTSD $(\mathrm{N}=456)$

\begin{tabular}{|c|c|c|c|c|c|}
\hline Items (PCLM1-17) & Range & Mean & SD & Skewness & Kurtosis \\
\hline Re-experiencing (Factor 1) & 20 & 6.80 & 3.77 & & \\
\hline 1: Intrusive memories & 4 & 1.49 & 1.01 & 1.928 & 2.406 \\
\hline 2: Nightmares & 4 & 1.39 & .91 & 2.299 & 4.200 \\
\hline 3: Flashbacks & 4 & 1.25 & .73 & 3.095 & 9.064 \\
\hline 4: Psycho. Distress & 4 & 1.48 & 1,04 & 2.069 & 3.097 \\
\hline 5: Psycho. Reactivity & 4 & 1.32 & .84 & 2.609 & 5.885 \\
\hline Avoiding (Factor 2) & 8 & 2.60 & 1.57 & & \\
\hline 6. Thoughts/Feelings & 4 & 1.31 & .85 & 2.749 & 6.512 \\
\hline 7: Activities/Places/People & 4 & 1.31 & .87 & 2.844 & 6.997 \\
\hline Numbing (Factor 3) & 19 & 7.03 & 3.52 & & \\
\hline 8: Trauma-Related Amnesia & 4 & 1.33 & .84 & 2.648 & 6.058 \\
\hline 9: Diminished Interest & 4 & 1.69 & 1.14 & 1.354 & 0.360 \\
\hline 10: Detachment & 4 & 1.38 & .90 & 2.392 & 4.828 \\
\hline 11: Restricted Affect & 4 & 1.27 & .78 & 3.050 & 8.565 \\
\hline 12: Foreshortened Future & 4 & 1.46 & 1.05 & 2.149 & 3.266 \\
\hline Hyper-arousal (Factor 4) & 20 & 8.39 & 4.39 & & \\
\hline 13: Sleep difficulty & 4 & 2.23 & 1.46 & 0.610 & -1.218 \\
\hline 14: Irritability/Anger & 4 & 1.63 & 1.06 & 1.585 & 1.436 \\
\hline 15: Difficulty Concentrating & 4 & 1.63 & 1.009 & 1.549 & 1.134 \\
\hline 16: Hypervigilance & 4 & 1.41 & .98 & 2.259 & 3.787 \\
\hline 17: Exaggerated Startle & 4 & 1.52 & 1.06 & 1.880 & 2.236 \\
\hline PCLM Total & 66 & 23.73 & 10.25 & 2.260 & 5.780 \\
\hline
\end{tabular}

Table 3 lists internal consistency established by means of Cronbach's alpha coefficients for frequency total and subscale scores, which were very good (.810) and excellent (.926). The alphas represent the shared variance of the items within each factor. In contrast, the squares of intercorrelations of the subscales represent the shared variances across scales. This suggests that the subscales measured independent and distinct phenomena (Mueller \& Hancock, 2007). Similarly, intercorrelations among subscales are lower than internal consistency alphas. 
Table 3: $\quad$ Correlation Matrix among Subscales with Reliability

\begin{tabular}{lccccc}
\hline Factor Names & $\mathbf{1}$ & $\mathbf{2}$ & $\mathbf{3}$ & $\mathbf{4}$ & Total \\
\hline Reexperiencing (F1) & 1.00 & & & & \\
Avoiding (F2) & $.676^{* *}$ & 1.00 & & & \\
Numbing (F3) & $.702^{* *}$ & $.622^{* *}$ & 1.00 & & \\
Hyper-arousal (F4) & $.654^{* *}$ & $.540^{* *}$ & $.795^{* *}$ & 1.00 & \\
\hline PCLM Total Reliability (Cronbach's Alpha) & .902 & .838 & .810 & .835 & .926 \\
\hline
\end{tabular}

** Correlation is significant at $p<.01$ (1-tailed)

Table 4 presents structural elements of the model such as factor loadings with tvalues, and squared multiple correlations. Each PTSD item loads on its latent factor with factors ranging from .38 to .87 , which are all statistically significant with t-values ranging from 10.71 to 17.34 . The $\mathrm{R}^{2}$ values range from .32 to .68 , indicating between $32 \%$ and $68 \%$ of the variance on individual items can be accounted for by the latent factor to which they are consigned. Considering results that the selected fit indices reflect a goodfitting model and the factor loadings are statistically significant, the result confirms the factor structure of the PCL-M.

Table 5 summarizes the fit statistics comparing the results of different models. As most experts in SEM (Kline, 2011) have addressed that good model fit should not be interpreted as having 'truly proven' the hypothetical model, we tested several equivalent models which were published in previous studies with different samples. Considering theoretical and practical provision among five competing models, the four-factor intercorrelated model (4-factor $1^{\text {st }}$ order model) is the best fitted model $\left(\chi^{2} / \mathrm{df}=3.663\right.$, RMSEA $=.080, \mathrm{CFI}=.97, \mathrm{IFI}=.97$ ) based on the cut-off mentioned above. The 3 -factor model and 4-factor second-order model are also found to have a satisfactory fit with a cut-off of CFI, NFI, \& IFI >.95.

To establish convergent validity, a further Pearson correlation matrix (Table 6) shows statistically significant relationships between the four sub scales and related psychological and physical health conditions. As expected, the relationship between PTSD and depression are strongly and significantly correlated $(r=.726)$. With one insignificant relation between alcohol problems and avoiding symptoms, the total PTSD score is also statistically significantly associated with Alcohol problems $(\mathrm{r}=.219)$, General Health $(\mathrm{r}=.359)$, and total number of Medications $(\mathrm{r}=.435)$ at the significance level of .001 . To test concurrent validity, a t-test and f-test were used to clarify the relationship between the mean score on the PCL-M and the selected demographic variables. 
Table 4: $\quad$ Factor Loadings (Path Coefficient $(\boldsymbol{\beta})$, T-values $(\boldsymbol{t})$, and $\left.\boldsymbol{R}^{2}\right)$

\begin{tabular}{|c|c|c|c|c|c|}
\hline Items (PCLM 1-17) & Re-Experiencing & Avoiding & Numbing & Hyper-Arousal & $\mathbf{R}^{2}$ \\
\hline 1: Intrusive memories & $.70(17.42)$ & & & & .66 \\
\hline 2: Nightmares & $.59(16.94)$ & & & & .64 \\
\hline 3: Flashbacks & $.48(15.52)$ & & & & .56 \\
\hline 4: Psychological Distress & $.76(17.34)$ & & & & .66 \\
\hline 5: Psychological Reactivity & $.54(16.09)$ & & & & .59 \\
\hline 6: Thoughts/Feelings & & $.58(15.64)$ & & & .63 \\
\hline 7: Activities/Places/People & & $.56(16.04)$ & & & .66 \\
\hline 8: Trauma-Related Amnesia & & & $.44(10.71)$ & & .32 \\
\hline 9: Diminished Interest & & & $.75(13.89)$ & & .48 \\
\hline 10: Detachment & & & $.59(14.82)$ & & .53 \\
\hline 11: Restricted Affect & & & $.38(11.78)$ & & .37 \\
\hline 12: Foreshortened Future & & & $.71(15.35)$ & & .56 \\
\hline 13: Sleep difficulty & & & & $.87(11.82)$ & .38 \\
\hline 14: Irritability/Anger & & & & $.64(13.35)$ & .46 \\
\hline 15: Difficulty Concentrating & & & & $.85(17.59)$ & .68 \\
\hline 16: Hypervigilance & & & & $.60(14.45)$ & .51 \\
\hline 17: Exaggerated Startle & & & & $.75(15.34)$ & .56 \\
\hline
\end{tabular}

Note: All path coefficients are significant

Table 5: $\quad$ Summary of Fit Statistics with ML Estimation Method from Different Models

\begin{tabular}{llllllllllll}
\hline Models & $\chi^{2}$ & $\mathrm{df}$ & $\chi^{2 / \mathrm{df} \text { ratio }}$ & SRMR & GFI & AGFI & AIC & RMSEA & CFI & NFI & IFI \\
\hline 2-Factor A & 607.02 & 118 & 5.161 & .070 & .81 & .75 & 727.23 & .118 & .95 & .93 & .95 \\
2-Factor B & 663.07 & 118 & 5.619 & .074 & .79 & .72 & 825.09 & .128 & .94 & .93 & .94 \\
3-Factor & 486.09 & 116 & 4.190 & .059 & .86 & .81 & 540.28 & .096 & .96 & .95 & .96 \\
4-Factor A & $\mathbf{3 7 4 . 5 7}$ & $\mathbf{1 1 3}$ & $\mathbf{3 . 3 1 5}$ & $\mathbf{. 0 4 7}$ & $\mathbf{. 8 9}$ & $\mathbf{. 8 5}$ & $\mathbf{4 3 3 . 2 2}$ & $\mathbf{. 0 8 0}$ & $\mathbf{. 9 7}$ & $\mathbf{. 9 6}$ & $\mathbf{. 9 7}$ \\
4-Factor B & 421.29 & 115 & 3.663 & .057 & .88 & .84 & 471.52 & .086 & .97 & .95 & .97 \\
\hline
\end{tabular}


Table 6: $\quad$ Convergent and Discriminant Analyses

\begin{tabular}{|c|c|c|c|c|c|}
\hline Variables Name & Full PCLM & Re-experience & Avoiding & Numbing & Hyper-arousal \\
\hline \multicolumn{6}{|l|}{ Convergent } \\
\hline Depression & $.726^{* *}$ & $.570 * *$ & $.464 * *$ & $.715^{* *}$ & $.721 * *$ \\
\hline Alcohol Problem & $.219 * *$ & $.165^{* *}$ & $.063 \mathrm{~ns}$ & $.210 * *$ & $.342 * *$ \\
\hline General Health & $.359 * *$ & $.245^{* *}$ & $.189 * *$ & $.396^{* *}$ & $.413 * *$ \\
\hline Total \# of Medication & $.435 * *$ & $.277 * *$ & $.182 * * *$ & $.373 * * *$ & $.437 * * *$ \\
\hline \multicolumn{6}{|l|}{ Discriminant } \\
\hline Education & $.003 \mathrm{~ns}$ & $.008 \mathrm{~ns}$ & $.054 \mathrm{~ns}$ & $-.025 \mathrm{~ns}$ & $-.055 \mathrm{~ns}$ \\
\hline Income & $-.195 * *$ & $-.170 * *$ & $-.059 \mathrm{~ns}$ & $-.214 * *$ & $-.203 * *$ \\
\hline Marital Status & $.114^{*}$ & .024 & $-.027 \mathrm{~ns}$ & $.210 * *$ & $.103 * *$ \\
\hline \# of Household & $.058 \mathrm{~ns}$ & $.050 \mathrm{~ns}$ & $.033 \mathrm{~ns}$ & $.293 \mathrm{~ns}$ & $.084 \mathrm{~ns}$ \\
\hline \multicolumn{6}{|c|}{$\begin{aligned} \text { Notes: } & * * \text { Correlation is Significance } 0.01 \text { level (1-tailed) } \\
& * \text { Correlation is significant at the } 0.05 \text { level (1-tailed) } \\
& \text { ns }=\text { not significant }\end{aligned}$} \\
\hline
\end{tabular}

\section{DISCUSSION}

The present study provides additional support for the PCL-M as a highly reliable and valid measure of PTSD symptomatology. Further, the CFA result supports other research suggesting that avoidance and numbing symptoms of cluster $\mathrm{C}$ are more distinct than they are similar. The use of valid and reliable self-report PTSD instruments such as the PCL-M can improve the recognition, identification and diagnosis of PTSD. Consequently, the PCL-M may aid in the design of subsequent treatments for trauma survivors. An alternative model of PTSD indicating the separation of the DSM-IV symptoms of avoidance and numbing may be useful in structuring and developing treatment plans. The interrelationships between PTSD symptoms in designing and implementing treatment interventions may be important to consider given the support for factor solutions that link re-experiencing and avoidance or hyper-arousal and numbing as second order.

Consideration of alternative models of the structure of PTSD has important implications for clinical practice. Recently, researchers have suggested that treatment for persons diagnosed with PTSD may need to be customized to particular types of symptom presentations (Palmieri \& Fitzgerald, 2005). For example, there is some evidence to suggest that cognitive-behavioral treatment for PTSD may be less effective for individuals with higher levels of pre-treatment emotional numbing (Taylor, Federoff, Koch, Thordarson, Ecteau, \& Nicki, 2001). In subsequent research, Taylor and his colleagues found that using exposure therapy may show greater utility in symptom reduction for effortful avoidance than with symptoms of emotional numbing (Taylor, Thordarson, Maxfield, Federoff, Lovell, \& Ogrodniczuk, 2003).

Because the conflicts in Iraq and Afghanistan are ongoing, the full impact on the mental health of service members is not yet accurately known. According to the U.S. 
Department of Veterans Affairs, PTSD affects 6.8 percent of the general population. However, Iraq and Afghanistan veterans are returning with PTSD rates as high as 50 percent (Helmer, et al., 2007). Affected veterans can have multiple difficulties in daily functioning both at home and in their jobs. Many veterans may also face self-medication risks with alcohol and drug abuse (Yarvis, 2008). At a time of increasing PTSD among returning veterans from Iraq and Afghanistan, clinical social workers must pay special attention to the growing problem of untreated and undertreated war-related trauma as we know from the abundance of literature on Vietnam veterans that untreated PTSD contributes to significant health problems in older veterans (Kulka, et al., 1990).

The military has worked hard to inform returning veterans about what they might experience emotionally and how it may affect their families (Yarvis, Franklin, \& Dungee -Anderson, 2009). However, most veterans do not ask for help with PTSD symptoms out of shame or fear that it will negatively affect their career advancement. Even when taking into account the effect of combat exposure, it is critical to consider that a negative homecoming reception may prevent veterans from talking about their experiences or expressing their feelings about what happened while deployed. Further, veterans may also have a difficult time adjusting to their pre-deployment roles in the family as much as the family feels the pressure to adjust to a soldier's homecoming. Accordingly, family members can be instrumental in seeking out needed help if veterans are experiencing symptoms of PTSD, depression, or substance abuse (Cabrerra, Yarvis, \& Cox, in press; Jordan, et al., 1992).

While the present study has much strength, several limitations should be addressed. First, the study was a relatively small and purposeful sample restricted to older male veterans. Second, the missing cases were quite large even though we purposely selected, and we are curious whether it may be due to possible systematic or random errors. Additional research is required to further our understanding of the PTSD symptom structure in the context of varied, multiple, and chronic trauma exposure in peacekeeper populations. A population based longitudinal study should be conducted to assess returning troops' emotional experiences. Because the "post" in PTSD means that symptoms begin months or years later, some veterans as they age are experiencing late onset PTSD symptoms - memories, flashbacks, and nightmares - triggered by watching television news about the war or exposures to stimuli not previously experienced as aversive by the veteran. Future study direction should target more extensive diagnostic evaluation of the veteran's co-morbidity of psychological and social stressors including poorer health, unhealthy coping behaviors, and conflicts in family relationships, which may be led from unresolved past traumatic experiences.

\section{References}

Administration on Aging. (1999). A Profile of older Americans. Washington, DC: AARP

American Psychiatric Association. (2000). Diagnostic and Statistical Manual of Mental Disorders-IV-TR. Washington DC: Author.

Andrykowski, M. A., Cordova, M. J., Studts, J. L., \& Miller, T. W. (1998). Post-

traumatic Stress disorder after treatment of breast cancer: Prevalence of diagnosis and 
use of the PTSD Checklist - Civilian Version (PCL-C) as a screening instrument. Journal of Consulting and Clinical Psychology, 66(3), 586-590.

Asmundson, G. J. G., Frombach, I., McQuaid, J., Pedrelli, P., Lenox, R., \& Stein, M. B. (2000). Dimensionality of posttraumatic stress symptoms: A confirmatory factor analysis of DSM- IV symptom clusters and other symptom models. Behavior Research and Therapy, 38, 203-214.

Asmundson, G. J. G, Stein, M. B., \& McCreary, D. R. (2002). Posttraumatic stress disorder symptoms influence health status of deployed veterans and non-deployed military personnel. The Journal of Nervous and Mental Disease, 190(12), 807-815.

Asmundson, G. J. G., Wright, K. D., McCreary, D. R., \& Pedlar, D. (2003). Posttraumatic stress disorder symptoms in United Nations peacekeeper: An examination of factor structure in veterans with and without chronic pain. Cognitive Behavior Therapy, 32, 26-37.

Blanchard, E. B., Jones-Alexander, J., Buckley, T. C., \& Forneris, C. A. (1996). Psychometric properties of the PTSD Checklist (PCL). Behavior Research and Therapy, 34, 669-673.

Breslau, N., Davis, G. C., Peterson, E. L., \& Schultz, L. R. (2000). A second look at comorbitity in victims of trauma: The posttraumatic stress disorder-major depression connection. Biological Psychiatry, 48, 902-909.

Buckley, T. C., Blanchard, E. B., \& Hickling, E. J. (1998). A confirmatory factor analysis of posttraumatic stress symptoms. Behavior Research and Theory, 36, 1091-1099.

Cabrerra, D., Yarvis, J., \& Cox, A. (In press). Warrior families. In N. Ainspan \& W. Penk (Eds.), Guidance for families of service members. Annapolis, MD: United States Naval Institute.

Cook, J. M., Elhai, J. D., \& Arean, P. A. (2005). Psychometric properties of PTSD Checklist with older primary care patients. Journal of Traumatic Stress, 18(4), 371 376.

Cook, J. M., Elhai, J. D., Cassidy, E. L., Ruzek, J. I., Ram, D. G., \& Sheikh, J. I. (2005). Assessment of trauma exposure and post-traumatic stress in long-term care veterans: Preliminary data on psychometrics and post-traumatic stress disorder prevalence. Military Medicine, 17 (10), 862-866.

Cook, J. M., Riggs, D. S., Thompson, R. Coyne, J. C., \& Sheikh, J. I. (2004). Posttraumatic stress disorder and current relationship functioning among World War II ex-prisoners of war. Journal of Family Psychology, 18(1), 36-54.

Dirkzwager, A.J. E., Bramsen, I, \& Van Der Ploeg, H. M. (2005). Factors associated with posttraumatic stress among peacekeeping soldiers. Anxiety, Stress, and Coping, 18(1), 37-51.

Dobie, D. J., Kivlahan, D. R., Maynard, C., Bush, K. R., McFall, M., Epler, A. J., et al. (2002). Screening for post-traumatic stress disorder in female Veteran's Affairs 
patients: Validation of the PTSD checklist. General Hospital Psychiatry, 24, 367374.

DuHamel, K. N., Ostroff, J., Ashman, T., Winkel, G., Mundy, E. A., Keane, T. M., et al. (2004). Construct validity of the Posttraumatic Stress Disorder Checklist in cancer survivors: Analyses based on two samples. Psychological Assessment, 16, 255-266.

Elklit, A., \& Shevlin, M. (2007). The structure of PTSD symptom: A test of alternative models using confirmatory factor analysis. British Journal of Clinical Psychology, 46, 299-313.

Fitretoglu, D., Liu, A., Pedlar, D., \& Brunet, A. (2007). Mental health treatment seeking by military members with posttraumatic stress disorder: findings on rates, characteristics, and predictors from a nationally representative Canadian military sample. Canadian Journal of Psychiatry, 52(2), 103-110.

Forbes, D., Creamer, M., \& Biddle, D. (2001). The validity of the PTSD checklist as measure of symptomatic change in combat-related PTSD. Behavior Research and Therapy, 39, 977-986.

Forbes, D., Creamer, M., Hawthorne, G., Allen, N., \& McHugh, T. (2003). Comorbidity as a predictor of symptoms change after treatment in combat-related posttraumatic stress disorder. Journal of Nervous and Mental Disease, 191 (2), 93-99.

Gray, M. J., Bolton, E. E., \& Litz, B. T. (2004). A longitudinal analysis of PTSD symptom course: Delayed-onset PTSD in Somalia peacekeepers. Journal of Consulting and Clinical Psychology, 72(5), 909-913.

Helmer, D.A., Rossignol, M., Agarwal, R., Teichman, R., \& Lange, G. (2007). Health and exposure concerns of veterans deployed to Iraq and Afghanistan. Journal of Occupational and Environmental Medicine, 49, 475-480.

Hoge, C. W., Auchterlonie, J. L., \& Milliken, C. S. (2006). Mental health problems, use of mental health services, and attrition from military service after returning from deployment to Iraq or Afghanistan. Journal of the American Medical Association, 295(5), 1023-1032.

Horowitz, M., Wilner, N., \& Alvarez, W. (1979). Impact of Event Scale: A measure of subjective stress. Psychosomatic Medicine, 41, 209-218.

Hu, L., \& Bentler, P. M. (1999). Cutoff criteria for fit indexes in covariance structure analysis: Conventional criteria versus new alternate. Structural Equation Modeling, 6(1), 1-55.

Jordan, B. K., Marmar, C. R., Fairbank, J. A., Schlenger, W. E., Kulka, R. A., Hough, R. L., et al. (1992). Problems in families of male Vietnam veterans with posttraumatic stress disorder. Journal of Consulting and Clinical Psychology, 60, 916-926.

Keane, T. M., Caddell, J. M., \& Taylor, K. L. (1988). Mississippi scales for combatrelated posttraumatic stress disorder; three studies in reliability and validity. Journal of Consulting and Clinical Psychology, 56, 85-90. 
Keen, S. M., Kutter, C. J., Niles, B. L., \& Krinsley, K. E. (2008). Psychometric properties of PTSD Checklist in sample of male veterans. Journal of Rehabilitation Research \& Development, 45(3), 465-474.

Kessler, D. C., Sonnega, A., Bromet, E., Huges, M., \& Nelson, C. B. (1995).

Posttraumatic stress disorder in the national comorbidity survey. Archives of General Psychiatry, 52, 1048-1060.

Kline, R. B. (2011). Principles and practice of Structural Equation Modeling (3 ${ }^{\text {rd }}$ ed.). New York: Guilford.

Kulka, R. A., Schlenger, W. E., Fairbank, J. A., Hough, R. L., Jordan, B. K., Marmar, C. R., et al. (1990). Trauma and the Vietnam War generation: Report of findings from the National Vietnam Veterans Readjustment Study. New York: Brunner/Mazel.

Mehlum, L., \& Weisaeth, L. (2002). Predictors of posttraumatic stress reactions in Norwegian U.N. Peacekeepers 7 years after service. Journal of Traumatic Stress, 15(1), 17-26.

Mueller, R. O., \& Hancock, G. R. (2007). Structural equation modeling with SIMPLIS: A first course. Chicago, IL: Scientific Software International.

Musick, M. A., (1996). Religion and subjective health among black \& white elders. Journal of Health and Social Behavior, 37, 221-238.

Palmieri, P. A., \& Fitzgerald, L. F. (2005). Confirmatory factor analysis of posttraumatic stress symptoms in sexually harassed women. Journal of Traumatic Stress, 18, 657666.

Radloff, L. (1977). The CES-D Scale: A self-report depression scale for research in the general population. Applied Psychological Measures, 1, 385-401.

Radloff, L. S., \& Terri, L. (1986). Use of the Center for Epidemiological Studies Depression Scale with older adults. Clinical Gerontologist, 5(1-2), 119-136.

Richardson, J. D., Naifeh, J. A., \& Elhai, J. D. (2007). Posttraumatic stress disorder and associated risk factors in Canadian peacekeeping veterans with health-related disabilities. The Canadian Journal of Psychiatry, 52(8), 510-518.

Richardson, C. and Waldrop, J. (2003) Veterans: 2000. Census 2000 Brief. Washington, DC: US Census Bureau.

Schinka, J. A., Brown, L. M., Borenstein, A. R., \& Mortimer, J. A. (2007). Confirmatory factor analysis of the PTSD checklist in the elderly. Journal of Traumatic Stress, 20(3), 281-289.

Schnurr, P. P., Spiro, III, A., Vielhauer, M. J., Findler, M. N., \& Hamblen, J. L. (2002). Trauma in the lives of older men: Findings from the Normative Aging Study. Journal of Clinical Geropsychology, 8(3), 175-187. 
Simms, L. J., Watson, D., \& Doebbelling, B. N. (2002). Confirmatory factor analyses of posttraumatic stress symptoms in deployed and non-deployed veterans of the Gulf War. Journal of Abnormal Psychology, 111, 637-647.

Taylor, S., Federoff, I. C., Koch, W. J., Thordarson, D. S., Ecteau, G., \& Nicki, R. M. (2001). Posttraumatic stress disorder arising after road traffic collision: Patterns of response to cognitive behavioral therapy. Journal of Consulting and Clinical Psychology, 69, 541-551.

Taylor, S., Kuch, K., Koch, W. J., Crockett, D. J., \& Passey, G. (1998). The structure of posttraumatic stress symptoms. Journal of Abnormal Psychology, 107, 154-160.

Taylor, S., Thordarson, D. S., Maxfield, L., Federoff, I. C., Lovell, K., \& Ogrodniczuk, J. (2003). Comparative efficacy, speed, and adverse effects of three PTSD treatments: Exposure therapy, EMDR, and relaxation training. Journal of Consulting and Clinical Psychology, 71, 330-338.

Veterans Affairs Canada. (1999). Overview of VAC's CF clients care needs. Montreal: Creatic+.

Weathers, F. W., Litz, B., Herman, D. S., Huska, J. A., \& Keane, T. M. (1993). The PTSD Checklist: Reliability, validity, and diagnostic utility. Paper presented at the Annual Meeting of the International Society for Traumatic Stress Studies, San Antonio, TX.

World Health Organization. (2001). The Alcohol Use Disorders Identification Test (AUDIT): Guidelines for use in primary care $\left(2^{\text {nd }}\right.$ ed.). Retrieved from http://whqlibdoc.who.int/hq/2001/WHO_MSD_MSB_01.6a.pdf

Yarvis, J. (2008). Subthreshold PTSD in veterans with different levels of traumatic stress: Implications for prevention and treatment with populations with PTSD. Saarbrucken, Germany: VDM Verlag Dr. Muller Publishers.

Yarvis, J., Bordnick, P., Spivey, C., \& Pedlar, D. (2005). Subthreshold PTSD: A comparison of depression, alcohol and physical health problems in Canadian peacekeepers with different levels of traumatic stress. Stress, Trauma, \& Crisis: An International Journal, 8(2-3), 195-213.

Yarvis, J. S., Franklin, K., \& Dungee-Anderson, D. (2009, November). The triple trauma matrix of military conflict: Deployment, PTSD and reintegration. Paper presented at the Council of Social Work Education Annual Meeting, San Antonio, TX

Yarvis, J. S., \& Schiess, L. (2008). Subthreshold PTSD as a predictor of depression, alcohol use, and health problems in soldiers. Journal of Workplace Behavioral Health, 23(4), 395-424.

Yeager, D. E., Magruder, K. M., Knapp, R. G., Nicholas, J. S., \& Frueh, B. C. (2007). Performance characteristics of Posttraumatic Stress Disorder Checklist and SPAN in Veterans Affairs primary care settings. General Hospital Psychiatry, 29(4), 294-301. 


\section{Author's note:}

Address correspondence to: Lieutenant Colonel Jeffrey Yarvis, Deputy Commander for Behavioral Health, Dewitt Healthcare Network, Fort Belvoir, VA 22060. E-mail:

Jeffrey.yarvis@us.army.mil. 